\title{
Integrity of mGluR-LTD in the Associative/Commissural Inputs to CA3 Correlates with Successful Aging in Rats
}

\author{
Sunggu Yang, ${ }^{1}$ Andrea Megill, ${ }^{1,2}$ Alvaro 0. Ardiles, ${ }^{1,3}$ Sarah Ransom, ${ }^{1}$ Trinh Tran, ${ }^{1}$ Ming Teng Koh, ${ }^{4}$ Hey-Kyoung Lee, ${ }^{1,2}$ \\ Michela Gallagher, ${ }^{4}$ and Alfredo Kirkwood ${ }^{1,2}$ \\ ${ }^{1}$ The Mind/Brain Institute, Johns Hopkins University, Baltimore, Maryland 21218, 2Department of Neuroscience, Johns Hopkins University, Baltimore, \\ Maryland 21205, ${ }^{3}$ Centro Interdisciplario de Neurociencias de Valparaiso, Valparaiso, Chile, and ${ }^{4}$ Department of Psychological and Brain Sciences, Johns \\ Hopkins University, Baltimore, Maryland 21218
}

The impact of aging on cognitive capabilities varies among individuals ranging from significant impairment to preservation of function on par with younger adults. Research on the neural basis for age-related memory decline has focused primarily on the CA1 region of the hippocampus. However, recent studies in elderly human and rodents indicate that individual differences in cognitive aging are more strongly tied to functional alterations in CA3 circuits. To examine synaptic plasticity in the CA3 region, we used aged rats behaviorally characterized in a hippocampal-dependent task to evaluate the status of long-term potentiation and long-term depression (LTP and LTD) in the associative/commissural pathway $(\mathrm{A} / \mathrm{C} \rightarrow \mathrm{CA} 3)$, which provides the majority of excitatory input to $\mathrm{CA} 3$ pyramidal neurons. We found that, unlike in CA1 synapses, in A/C $\rightarrow$ CA3 LTP is minimally affected by age. However, two forms of LTD, involving NMDA and metabotropic glutamate receptors (mGluR), are both greatly reduced in age-impaired rats. Age-unimpaired rats, in contrast, had intact mGluR LTD. These findings indicate that the integrity of mGluR-LTD at A/C $\rightarrow$ CA3 inputs may play a crucial role in maintaining the performance of CA3 circuitry in aging.

\section{Introduction}

The encoding of new memories is thought to involve mechanisms of synaptic plasticity like long-term potentiation (LTP) and long-term depression (LTD) (Bliss and Collingridge, 1993; Bear, 1999). Previous research, primarily conducted at the Schaffer collateral inputs to CA1 cells $(\mathrm{SC} \rightarrow \mathrm{CA} 1)$ has identified alterations in LTP and LTD that are associated with age-related cognitive decline (Landfield and Lynch, 1977; Deupree et al., 1993; Norris et al., 1996; Shankar et al., 1998; Schulz et al., 2002; Tombaugh et al., 2002; Lee et al., 2005; Burke and Barnes, 2006; Boric et al., 2008). While the $\mathrm{SC} \rightarrow \mathrm{CA} 1$ pathway has been a preferred model to study the cellular basis of cognitive impairment because the mechanisms of LTP and LTD have been thoroughly characterized in normal young rats, a wealth of evidence at both the systems and molecular levels indicates that differences in cognitive aging are strongly evident in hippocampal circuits and subregions outside CA1.

The CA3 region, which computational models place at the center of a dynamic competition between the processes of pattern completion and pattern separation (O'Reilly and Norman, 2002;

\footnotetext{
Received March 12, 2013; revised June 18, 2013; accepted June 24, 2013.

Author contributions: A.K. designed research; S.Y., A.M., A.O.A., S.R., M.T.K., and T.T. performed research; S.Y., A.O.A., and S.R. analyzed data; H.-K.L., M.G., and A.K. wrote the paper.

This work is supported by Grant 5R01AG034606 to A.K. and P01-AG09973 to M.G.

Correspondence should be addressed to either of the following: Alfredo Kirkwood, Department of Neuroscience, Mind/Brain Institute, Johns Hopkins University, Dunning Hall 350, 3400 North Charles Street, Baltimore, MD 21218, E-mail: Kirkwood@jhu.edu; or Michela Gallagher, Department of Psychological and Brain Sciences, Johns Hopkins University, Ames Hall 216B, 3400 North Charles Street, Baltimore, MD 21218. E-mail: michela@jhu.edu.

DOI:10.1523/JNEUROSCI.1086-13.2013

Copyright $\odot 2013$ the authors $\quad 0270-6474 / 13 / 3312670-09 \$ 15.00 / 0$
}

Norman and O'Reilly, 2003), may play a particularly critical role in determining aging outcomes. In vivo recording studies in aged rats with poor memory demonstrate that CA3 neurons have substantially elevated firing rates and fail to rapidly encode new information in the manner observed in young adults (Wilson et al., 2005). This condition is proposed to reflect a predominance of pattern completion mediated by the associative/commissural projection $(\mathrm{A} / \mathrm{C} \rightarrow \mathrm{CA} 3)$, which provides most of the excitatory drive onto CA3 pyramidal neurons. Behavioral studies in elderly humans and patients with amnestic mild cognitive impairment (aMCI), together with the use of functional magnetic resonance imaging (fMRI), suggest that a similar condition occurs in humans with age-related memory impairment (Yassa et al., 2010, 2011; Bakker et al., 2012).

We investigated the status of LTP and LTD in the associative/ commissural synapses onto $\mathrm{CA} 3(\mathrm{~A} / \mathrm{C} \rightarrow \mathrm{CA} 3)$ in aged LongEvans rats. All animals were initially characterized to identify aged rats with behavioral impairment and aged cohorts with preserved hippocampal-dependent spatial learning and memory. Our results indicated that unlike $\mathrm{SC} \rightarrow \mathrm{CA} 1$, aging minimally affects LTP induction in A/C $\rightarrow$ CA3, while it severely reduces LTD in aged rats with memory impairment. Although reductions in the NMDA receptor (NMDAR)-dependent form of LTD were observed equally across the spectrum of aged rat performance, a form of LTD that depends on the activation of metabotropic glutamate receptors (mGluR-LTD) was fully maintained in unimpaired aged rats but lost in aged rats with behavioral impairment. These findings suggest that successful aging requires the preservation of mGluR-dependent plasticity in the $\mathrm{A} / \mathrm{C} \rightarrow \mathrm{CA} 3$ pathway, contributing to a functional balance in the computa- 
A

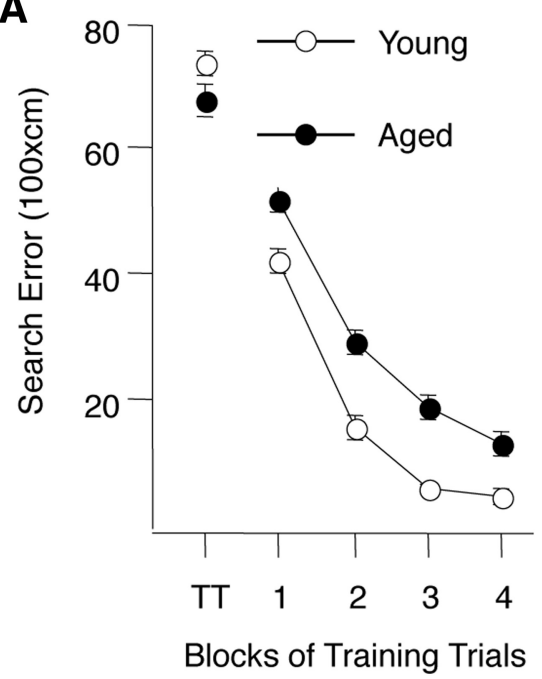

B

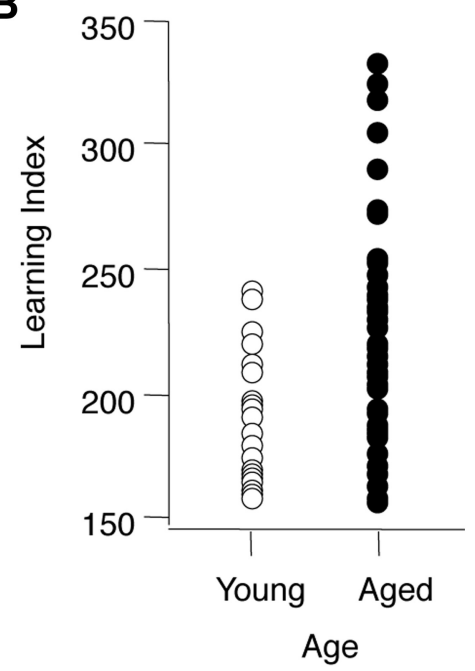

Figure 1. Behavioral characterization of young and aged rats. $A$, Training trial performance in the Morris water maze for all rats, young $(\bigcirc)$ and aged $(-)$ used in this research. Note that the age groups do not differ on the first training trial (TT) but young rats are more proficient in learning to escape. $\boldsymbol{B}$, Range of performance for young and aged rats used in the study. Aged rats that fell within the normative range of young performance (index $<240$ ) were designated unimpaired and aged rats with higher scores were designated impaired. Learning index scores were computed from probe trials for each individual rat (see text and Gallagher et al., 1993 for detail).

tional processes mediated within the CA3 region of the hippocampus.

\section{Materials and Methods}

Behavioral assessment. Male Long-Evans outbred rats obtained pathogen free from Charles River Laboratories were 6 months (young) or 24 months (aged) of age at the time of behavioral characterization for spatial learning in a water maze $\left(1.83 \mathrm{~m}\right.$ diameter, opaque water at $\left.27^{\circ} \mathrm{C}\right)$. During an $8 \mathrm{~d}$ period, in sessions consisting of three trials a day with a $60 \mathrm{~s}$ intertrial interval, rats were trained to locate a camouflaged platform that remained in the same location $2 \mathrm{~cm}$ below the water surface. During a training trial, the rat was placed in the water at the perimeter of the pool and allowed $90 \mathrm{~s}$ to locate the escape platform. If at $90 \mathrm{~s}$ the rat failed to escape on a trial, it was placed onto the platform and allowed to remain there for $30 \mathrm{~s}$. The position of entry for the animal was varied at each trial. Every sixth trial consisted of a free swim ("probe trial"), which served to assess the development of a spatially localized search for the escape platform. During probe trials the rat was allowed to swim a total of $30 \mathrm{~s}$ with the escape platform retracted to the bottom of the pool. After $30 \mathrm{~s}$, the platform was raised so that the rat could complete escape on the trial. A "behavioral index," which was generated from the proximity of the rat to the escape platform during probe trial performance, was used in correlational analysis with the neurobiological data. This index is the sum of weighted proximity scores measured during probe trials; low scores reflect search near the escape platform whereas high scores reflect search farther away from the target (Gallagher and Nicolle, 1993). Thus, the behavioral index provides a measure that is based on search accuracy independent of escape velocity (Gallagher et al., 1993). "Search error" during training trials refers to the deviation from a direct path to the platform and provided an additional measure for behavioral analysis (Gallagher and Nicolle, 1993). Cue training (visible escape platform; six trials) occurred on the last day of training to test for sensorimotor and motivational factors independent of spatial learning. Rats that failed to meet a cue criterion of locating the visible platform within an average of 20 s over six trials were excluded from the experiments.

Electrophysiology. Behaviorally characterized young (6 months) and aged (24 months) rats were deeply anesthetized with isoflurane, and under pentobarbital anesthetic agent were perfused transcardially with cold artificial CSF (ACSF; $75 \mathrm{ml}$ at $25 \mathrm{ml} / \mathrm{min}$ ) before decapitation. Brains were removed quickly and coronal hippocampal slices $(400 \mu \mathrm{M})$

were made as described previously (Boric et al., 2008) in ice-cold dissection buffer containing the following (in $\mathrm{mm}$ ): 212.7 sucrose, $2.6 \mathrm{KCl}$, $1.23 \mathrm{NaH}_{2} \mathrm{PO}_{4}, 26 \mathrm{NaHCO}_{3}, 10$ dextrose, 3 $\mathrm{MgCl}_{2}$, and $1 \mathrm{CaCl}_{2}$ bubbled with a mixture of $5 \% \mathrm{CO}_{2}$ and $95 \% \mathrm{O}_{2}$. The slices then recovered for $1 \mathrm{~h}$ at room temperature in ACSF containing the following (in $\mathrm{mm}$ ): $124 \mathrm{NaCl}, 5 \mathrm{KCl}$, $1.25 \mathrm{NaH}_{2} \mathrm{PO}_{4}, 26 \mathrm{NaHCO}_{3}, 10$ dextrose, 1.5 $\mathrm{MgCl}_{2}$, and $2.5 \mathrm{CaCl}_{2}$ bubbled with a mixture of $5 \% \mathrm{CO}_{2}$ and $95 \% \mathrm{O}_{2}$.

All recordings were done in a submerged recording chamber superfused with ACSF (30 \pm $\left.0.5^{\circ} \mathrm{C}, 2 \mathrm{ml} / \mathrm{min}\right)$. Synaptic responses were evoked by stimulating the A/C with $0.2 \mathrm{~ms}$ pulses delivered through concentric bipolar stimulating electrodes, and recorded extracellularly in the stratum radiatum of the CA3 subfield. Both the stimulation and recording electrodes were positioned in the stratum radiatum of CA3b (toward CA1) (see Fig. 2A, top). To check for the effective isolation of the $\mathrm{A} / \mathrm{C} \rightarrow \mathrm{CA} 3$ pathway, we superfused the group II mGluR agonist $\left(2 S, 2^{\prime} R, 3^{\prime} R\right)-2-\left(2^{\prime}, 3^{\prime}-\right.$ dicarboxycyclopropyl)glycine (DCGIV' 100 $\mu \mathrm{M})$ at the end of the experiment. Entorhinal and mossy fiber inputs, but not $\mathrm{A} / \mathrm{C}$ input, are modulated by presynaptic type II mGluRs (Tsukamoto et al., 2003). Therefore experiments showing a decreased response upon DCGIV were discarded. Baseline responses were recorded at $0.033 \mathrm{~Hz}$ using an intensity that evoked a 1/2 max field response. NMDAR-dependent LTP (NMDAR-LTP) was induced by four theta burst stimulation (TBS; 10 trains of four pulses burst at $100 \mathrm{~Hz} ; 200 \mathrm{~ms}$ interburst interval) delivered at $0.1 \mathrm{~Hz}$. Voltagegated calcium channel-dependent LTP (VGCC-LTP) was induced with four $200 \mathrm{~Hz}$ epochs delivered at $0.2 \mathrm{~Hz}$ in presence of an NMDAR antagonist, DL-APV $(100 \mu \mathrm{M})$. NMDAR-LTD was induced with $1 \mathrm{~Hz}$ for 15 min while mGluR-LTD was induced by delivering paired pulses $(50 \mathrm{~ms}$ interstimulus interval) repeated at $1 \mathrm{~Hz}$ for $15 \mathrm{~min}$ in the presence of a blocker of NMDAR (100 $\mu$ M DL-APV). Chemically induced mGluR-LTD was generated by the application of DHPG $(5-50 \mu \mathrm{M})$ for $10 \mathrm{~min}$. LTP and LTD magnitude was calculated as the average (normalized to baseline) of the responses recorded 50-60 min after conditioning stimulation, corresponding to the early phase of LTP and LTD, which is sometimes referred as early LTP/D, to distinguish it from late LTP/LTD (Frey et al., 1993; Sajikumar et al., 2007). Statistical significance was evaluated with $t$ test, ANOVA test,and Kolmogorov-Smirnov test (KS).

\section{Results}

To determine the effects of aging on synaptic plasticity in the CA3 subfield of the hippocampus we studied the induction of NMDAR-dependent and NMDAR-independent forms of LTP and LTD in slices prepared from behaviorally characterized young (6 months old) and aged (24 months old) outbred LongEvans rats. The results of the behavioral assessment are shown in Figure 1. There was no difference in performance on the first trial of the training, before the rats had experienced escaping to the hidden platform in the water maze (Fig. 1A, TT data point). During training, however, aged rats were less proficient in learning to locate the platform. A two-way ANOVA (Age $\times$ Trial Block) confirmed that performance improved over the course of training (Trial Block $F_{(3,312)}=165.24, p<0.0001$ ) but yielding a significant difference between age groups $\left(\right.$ Age $F_{(1,312)}=70.05$, $p<0.0001)$. The interaction between Trial Block and Age was not significant $\left(F_{(3,312)} 1.089, p=0.354\right)$. The learning index scores (Fig. $1 B$ ), computed from a key measure of search accuracy during interleaved probe trials, also differed according to age $(p<$ 
A

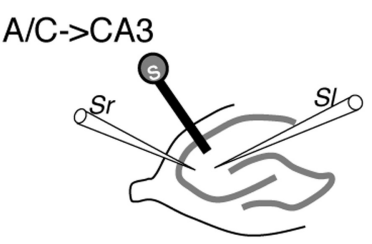

$\mathrm{TA} \rightarrow \mathrm{CA} 3$

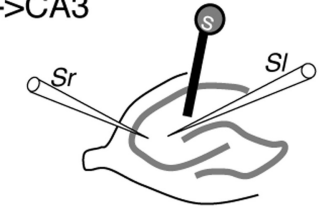

C

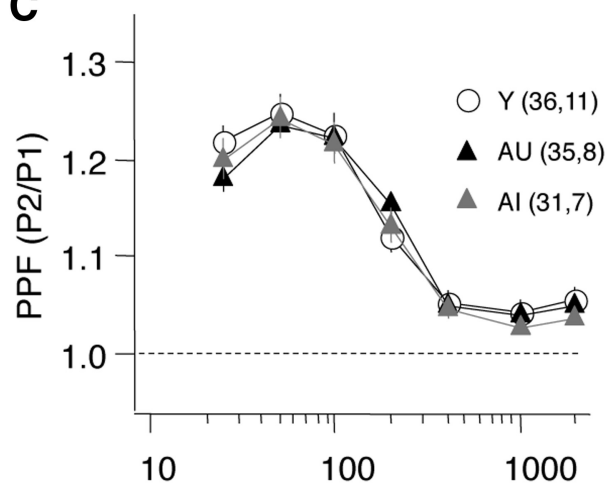

I.S.I. (msec)
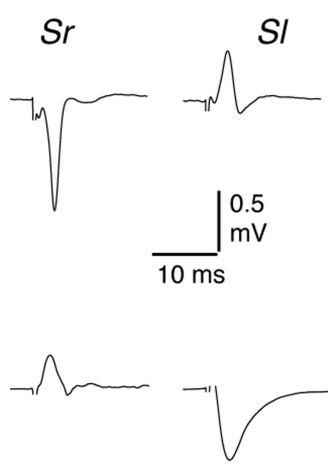

D

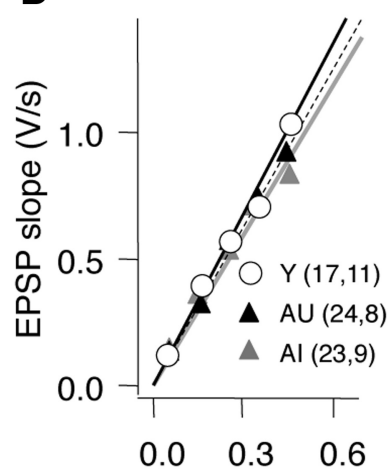

F.V. (mV)

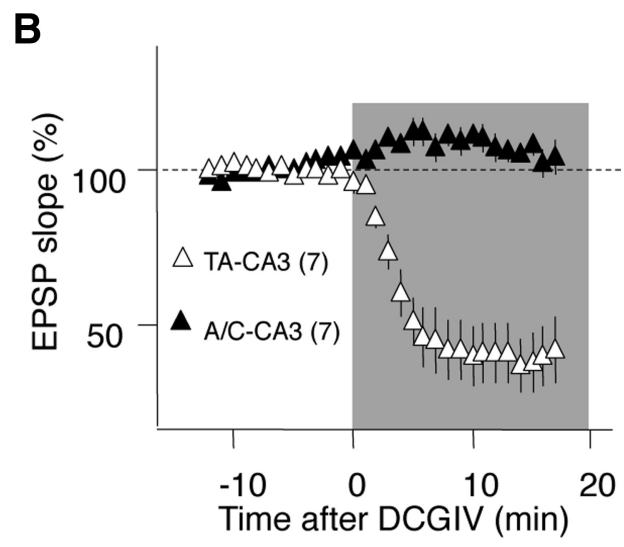

E

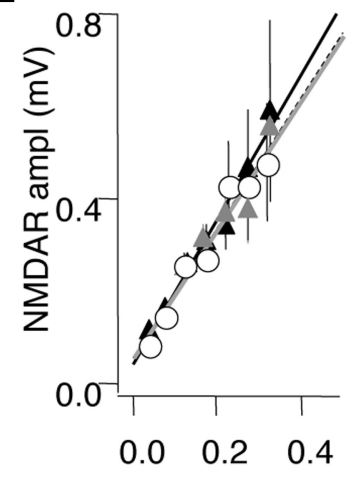

F.V. (mV)

Figure 2. Age does not affect the basal synaptic strength of the $A / C$ inputs to $C A 3$. $A$, Schematics of the stimulus-recording configuration to differentiate $A / C \rightarrow C A 3$ from $T A \rightarrow C A 3$. For $\mathrm{A} / \mathrm{C} \rightarrow \mathrm{CA}$ (top) stimulation in stratum radiatum (Sr) toward CA1 evokes a response in the Sr, but not in the stratum lacunosum (SI). For TA $\rightarrow$ CA3 stimulation in the $S \mathrm{I}$ near the hippocampal fissure evokes a response in the SI, but not in the Sr. $\boldsymbol{B}$, The type II mGluR agonist DCGIV $(100 \mu \mathrm{M})$ selectively depresses the $\mathrm{TA} \rightarrow \mathrm{CA} 3(\triangle)$, but not $\mathrm{A} / \boldsymbol{C} \rightarrow \mathrm{CA} 3$ inputs $(\boldsymbol{\Delta})$. $\mathbf{C}-\boldsymbol{E}$, Age does not affect PPF in the $A / C \rightarrow$ CA3 inputs at any interstimulus intervals (I.S.I.) (C), nor does it affect the relationship between the fiber volley amplitude (F.V.) with the EPSP slope (D) or with the amplitude of the pharmacologically isolated NMDAR response (10 $\mu \mathrm{MNBQX}$ and $0 \mathrm{~mm} \mathrm{MgCl}$ ) (E). Data in $C-E$ represent average results for young $(\mathrm{Y}, \bigcirc)$, aged impaired (Al, gray triangles), and aged unimpaired (AU: black triangles) rats. The linear fit of the data in $\boldsymbol{D}$ and $\boldsymbol{E}$ was not significantly different among the age groups. The number of slices and rats is indicated in parenthesis.

0.0001). In agreement with previous research in this model, the aged rats displayed a wide spectrum of outcomes, with many aged rats performing on par with young adults and a substantial group performing outside the range of young performance (Fig. 1B). Aged rats performing outside the range of the young group were designated aged impaired, while those performing on par with young adults were designated aged unimpaired.

\section{Basal synaptic transmission in the $\mathrm{A} / \mathrm{C} \rightarrow \mathrm{CA} 3$ pathway is not affected by age}

This study focused on the A/C inputs onto CA3 pyramidal neurons $(\mathrm{A} / \mathrm{C} \rightarrow \mathrm{CA} 3$, terminating in the stratum radiatum), yet $\mathrm{CA} 3$ neurons also receive excitatory inputs from the entorhinal cortex via the temporoammonic pathway ( $\mathrm{TA} \rightarrow \mathrm{CA} 3$, terminating in the stratum lacunosum-moleculare) and from granule cells in the dentate gyrus via the mossy fibers $(\mathrm{MF} \rightarrow \mathrm{CA} 3$, terminating in the stratum lucidum). Since these inputs terminate at different strata within $\mathrm{CA} 3$, the $\mathrm{A} / \mathrm{C} \rightarrow \mathrm{CA} 3$ pathway can be selectively studied by placing the stimulating and recording electrodes in the stratum radiatum (Fig. $2 A$ ). Importantly, presynaptic release in $\mathrm{TA} \rightarrow \mathrm{CA} 3$ and the $\mathrm{MF} \rightarrow \mathrm{CA} 3$ synapses, but not in the $\mathrm{A} / \mathrm{C} \rightarrow \mathrm{CA} 3$ synapses, is negatively controlled by presynaptic mGlu2 receptors (Shigemoto et al., 1997). As shown in Figure 2B, bath application of a type II mGluR agonist ( $1 \mu \mathrm{M}$ DCGIV) reduced the slope of the TA $\rightarrow$ CA3 EPSP $(38.7 \pm 10.28 \%$ of baseline; $n=9$; $t$ test: $p=0.001$ ), but not the A/C $\rightarrow$ CA3 EPSP
$(104.50 \pm 5.83 \% ; n=8 ; p=0.8)$. Those results confirmed the selective activation of the $\mathrm{A} / \mathrm{C} \rightarrow \mathrm{CA} 3$ synapses under our experimental conditions.

Next, we evaluated how aging affects several measures of basal synaptic transmission in the $\mathrm{A} / \mathrm{C} \rightarrow \mathrm{CA} 3$ pathway as described previously (Lee et al., 2005). The paired-pulse facilitation (PPF) ratio, which provides an estimate of changes in presynaptic release, was not significantly different among the three groups (Young, Y; Aged Impaired, AI; and Aged Unimpaired, AU) over a wide range of interstimulus intervals (Fig. 2C; repeatedmeasures ANOVA: $\left.F_{(2,594)}=0.130 ; p=0.88\right)$. Similarly, age did not affect the relationship between the fiber volley amplitude and the slope of the EPSP, which provides a measure of synaptic strength (Fig. 2D), or with the amplitude of the pharmacologically isolated NMDAR-mediated response (Fig. 2E). These observations indicate that basal synaptic transmission in the $\mathrm{A} / \mathrm{C} \rightarrow \mathrm{CA} 3$ pathway of aged rats is not different from that of young adult rats.

\section{Aging does not affect NMDAR-LTP but reduces VGCC-LTP in the AI group}

We have shown that at the $\mathrm{SC} \rightarrow \mathrm{CA} 1$ synapses, aging is associated with a reduction in NMDAR-LTP and with a selective enhancement of a form of VGCC-LTP in aged unimpaired rats. Therefore we evaluated the induction of these two forms of LTP in the aged $\mathrm{A} / \mathrm{C} \rightarrow \mathrm{CA} 3$ pathway, and used the same induction paradigms 

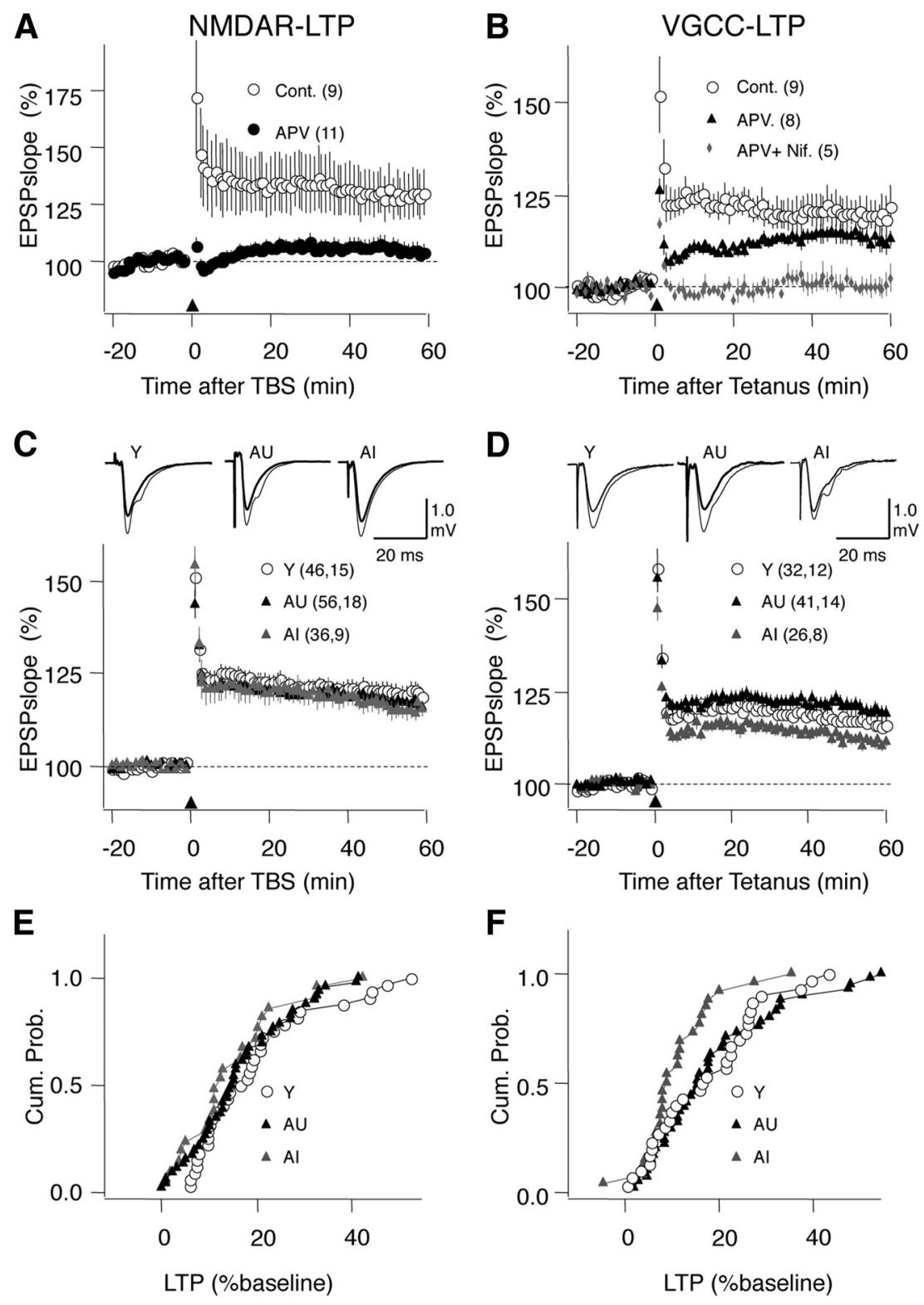

Figure 3. Effects of aging on NMDAR-LTP and VGCC-LTP. A, LTP induced with TBS (arrowhead) is blocked by $100 \mu M$ APV. B, LTP induced with a $200 \mathrm{~Hz}$ tetanus (arrowhead) is modestly reduced by $100 \mu \mathrm{m}$ APV and completely blocked by the further addition of the L-type $\mathrm{Ca}^{+2}$ channel blocker nifedipine $(10 \mu \mathrm{M})$. C, NMDAR-LTP is similar in the three groups. D, VGCC-LTP is modestly reduced in $\mathrm{Al}$, but not in AU rats. $\boldsymbol{E}$, Distributions of the NMDAR-LTP magnitude computed by pooling all the slices in Y, Al, and AU rats. $\boldsymbol{F}$, Similarly, distributions of the non-NMDAR-LTP for the three age groups. Young, $\mathrm{O}$; AU, black triangles; Al, gray triangles. The number of slices and rats is indicated in parentheses in each part. Traces on $\boldsymbol{C}$ and $\boldsymbol{D}$ : average of 10 consecutive responses recorded before (thick line) and $60 \mathrm{~min}$ after conditioning (thin line).

previously described for CA1: TBS to selectively induce NMDAR-LTP, and $200 \mathrm{~Hz}$ tetanic stimulation (see Materials and Methods) to induce VGCC-LTP (Grover and Teyler, 1990; Boric et al., 2008). As shown in Figure $3 A$, in the $\mathrm{A} / \mathrm{C} \rightarrow \mathrm{CA} 3$ pathway TBS induced robust LTP that was fully blocked by application of the NMDAR antagonist APV $(100 \mu \mathrm{M})$ in the bath (LTP in control: $128.78 \pm 10.56 \%$ of baseline at $60 \mathrm{~min}$ after TBS, $n=$ 9 slices; in APV: $104.91 \pm 3.81 \%, n=11$ slices; $p<0.05, t$ test; Fig. $3 A$ ). On the other hand, the $200 \mathrm{~Hz}$ tetanus induced a form of LTP that was minimally affected by APV $(100 \mu \mathrm{M})$ and was fully blocked when the L-type VGCC blocker nifedipine $(10 \mu \mathrm{M})$ was coapplied with APV (LTP in control: $119.60 \pm$ $4.60 \%, n=9$ slices; in APV $(100 \mu \mathrm{M}): 112.91 \pm 2.78 \%, n=8$ slices; in APV + nifedipine $(10 \mu \mathrm{M})$ : $100.46 \pm 2.68 \%, n=5$ slices; $F_{(2,19)}=$ $6.06 p<0.01$; Fig. $3 B$ ).

After confirming the efficacy and selectivity of these conditioning paradigms in the $\mathrm{A} / \mathrm{C} \rightarrow \mathrm{CA} 3$ pathway, we compared the magnitude of the two forms of LTP among the three groups. We found that on average the magnitude of the NMDAR-LTP did not differ as a function of age or cognitive status (Y: $122.67 \pm 2.23 \%, n=46$ slices, 15 rats; AU: $120.31 \pm 2.56 \%, n=56$ slices, 18 rats; AI: $120.17 \pm 2.11 \%, n=36$ slices, 9 rats; $\mathrm{ANOVA}, F_{(2,137)}=0.381, p=0.684$; Fig. $3 C$ ). Moreover, the distribution of the LTP magnitude in individual experiments was not different between the young and either the AI group (KS test: $p=0.41$ ) or the AU group (KS test: $p=0.73$; Fig. $3 E$ ). Next we considered the possibility that age might affect the saturation levels of NMDAR-LTP. In $\mathrm{SC} \rightarrow \mathrm{CA} 1$ a single TBS epoch is sufficient to nearly saturate NMDAR-LTP (Dudek and Bear, 1993; Lee et al., 1998). We confirmed that this is also the case in the $\mathrm{AC} \rightarrow \mathrm{CA} 3$ of $\mathrm{AI}$ rats: following an initial TBS epoch that produced substantial LTP ( $129.3 \pm 4.9 \%$ at $30 \mathrm{~min}, n=6$ ), a second TBS epoch did not result in further LTP (129.5 \pm 4.3 , paired $t$ test: $p=0.96$; data not shown). Thus, the results indicate that age does not affect NMDAR-LTP in AC $\rightarrow$ CA3 .

In contrast to NMDAR-LTP, the magnitude of the VGCC-LTP was significantly reduced in an analysis of the group data (Y: $116.63 \pm 2.16 \%, n=32$ slices, 12 rats; AU: $119.90 \pm 2.17 \%, n=41$ slices, 14 rats; AI: $111.55 \pm 1.57 \%, n=26$ slices, 8 rats; $\operatorname{ANOVA}, F_{(2,98)}=3.95, p=0.03$; Fig. $3 D)$, and this effect was attributable to the AI group ( $p<0.05$ Fisher post hoc test). Similarly, the distribution of individual LTP magnitudes of the young group was significantly different from the AI group (KS test: $p=0.04$ ), but not from the AU group (KS test: $p=0.78$; Fig. $3 F$ ). The present results markedly differ from those we previously described for CA1 in this model (Boric et al., 2008), where we found an age-related reduction in NMDAR-LTP with enhanced VGCC-LTP in the AU group. The contrasting results obtained previously in CA1 and currently in CA3 indicate that the effects of age on LTP are synapse specific, even for the same forms of LTP induced with the same paradigms and involving afferents from the same neurons.

\section{Aging reduces NMDAR-LTD in both aged groups and mGluR-LTD in the AI group}

Previously we showed that at the SC $\rightarrow$ CA1 synapses in this model, NMDAR-LTD is equally reduced in both AI and AU groups while mGluR-LTD is enhanced in the AU group. To evaluate the status of LTD at aged $\mathrm{A} / \mathrm{C} \rightarrow \mathrm{CA} 3$ synapses we studied the induction of the two forms of LTD using the conditioning paradigms as described for 
CA1: low-frequency stimulation (LFS: $1 \mathrm{~Hz}$, $15 \mathrm{~min}$ ) to induce NMDAR-dependent LTD, and paired-pulse LFS (ppLFS: $1 \mathrm{~Hz}, 15$ min, interpulse interval $=50 \mathrm{~ms}$ ) in the presence of $100 \mu \mathrm{M}$ APV to induce mGluRLTD (Lee et al., 2005). LFS induced robust NMDAR-LTD that was fully blocked by 100 $\mu \mathrm{M}$ APV in slices from young rats (LTD in control: $86.15 \pm 22.23 \%, n=7$ slices; APV: $98.66 \pm 2.20 \%, n=7$ slices; $p<0.05$, $t$ test; Fig. 4A). On the other hand, ppLFS plus APV induced robust mGluR-LTD which, as in CA1, was fully blocked by bath application of both type I mGluR antagonists LY $367385(100 \mu \mathrm{M})$ and the mGlu5 antagonist MPEP hydrochloride $(10 \mu \mathrm{M})$ (LTD in APV: $92.40 \pm 3.45 \%, n=7$ slices; APV + LY + MPEP: $101.53 \pm 4.25 \%, n=7$ slices; $p<0.05$, $t$ test; Fig. $4 B$ ).

Figure $4, C-F$, summarizes the ageassociated changes observed for these two forms of LTD. The magnitude of NMDARLTD was severely reduced by age (Y: $84.21 \pm 1.82 \%, n=34$ slices, 11 rats; AU: $95.43 \pm 1.25 \%, n=37$ slices, 13 rats; AI: $97.64 \pm 1.52 \%, n=23$ slices, 8 rats; ANOVA: $F_{(2,91)}=20.9, p<0.001$; Fig. $4 C, E$ ) to a similar extent in both $\mathrm{AI}$ and $\mathrm{AU}$ groups (Fisher post hoc). These differences were also reflected in the distributions of individual experiments (KS test for $\mathrm{Y}$ vs AI: $p<0.001$; KS test for Y vs AU: $p<0.001$ ). Next we consider the possibility that reduced levels of neuromodulators in slices from aged rats limited the induction NMDAR-LTD. In CA1 and cortical synapses Gq-coupled receptors promote NMDAR-LTD (Choi et al., 2005; Huang et al., 2012), and this type of modulation is an attractive candidate substrate for the behavioral gating of LTD observed in vivo (Hagena and Manahan-Vaughan, 2011). We found that stimulation of $\alpha 1$ adrenergic receptors (coupled to $\mathrm{Gq}$ ) with bath application of methoxamine ( $5 \mu \mathrm{M}$ during LFS), a manipulation that rescues the loss of NMDAR-LTD in the visual cortex after dark rearing (Guo et al., 2012), did not improve NMDAR-LTD in slices from AU rats $(96.50 \pm 1.68 \%$ of LTD, $n=6$ slices, 2 rats; data not shown).

The magnitude of mGluR-LTD was also reduced in the AI group but maintained in the AU group (Y: $83.88 \pm 1.55 \%, n=61$ slices, 17 rats; AU: $84.72 \pm 1.57 \%, n=54$ slices, 19 rats; AI: $93.22 \pm 1.22 \%$, $n=43$ slices, 16 rats; ANOVA: $F_{(2,152)}=9.996 ; p<0.005 ;$ KS test for $\mathrm{Y}$ vs AI: $p<0.001$; KS test for Y vs AU: $p=0.42$; Fig. $4 D, F)$. Altogether, these results indicate that the capacity to support LTD is severely reduced across induction protocols in the AI group but partially preserved in the AU group.

\section{Behavioral performance correlates with NMDAR-} independent forms of LTP/D

In the $\mathrm{SC} \rightarrow \mathrm{CA} 1$ pathway the magnitude of the NMDARdependent forms of LTP/D measured in a given individual was
NMDAR-LTD

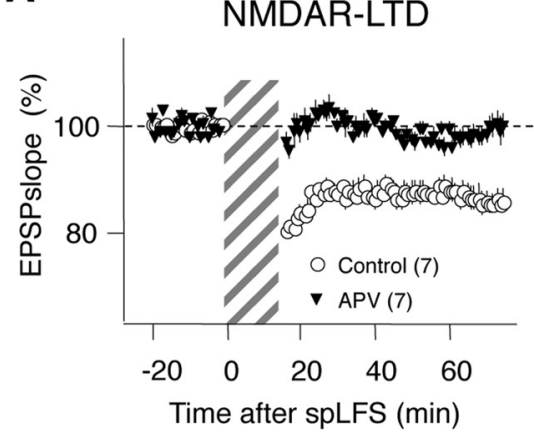

C

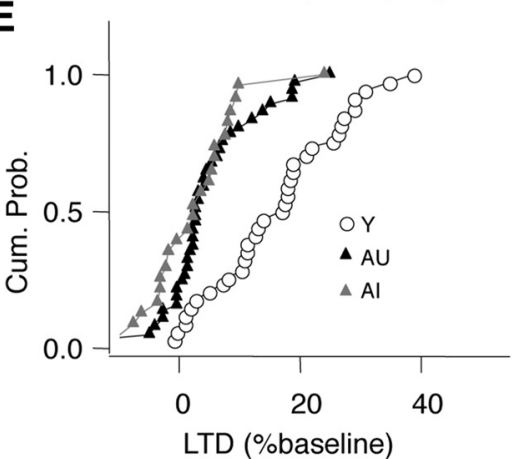

B

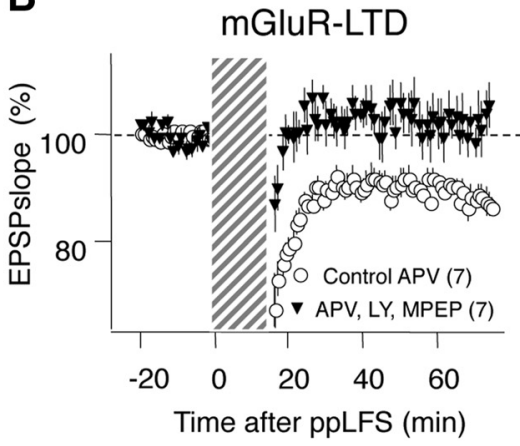

D

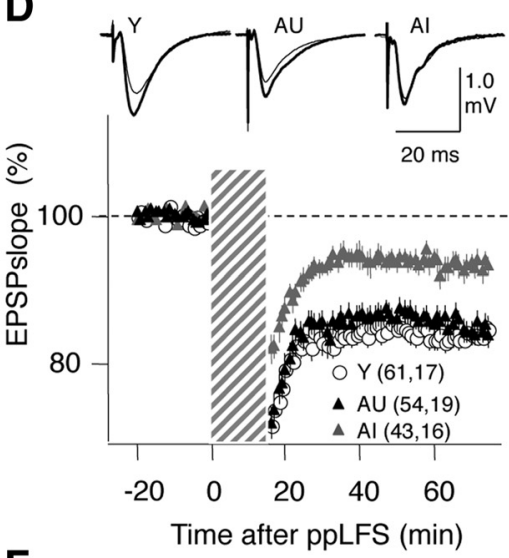

$\mathbf{F}$

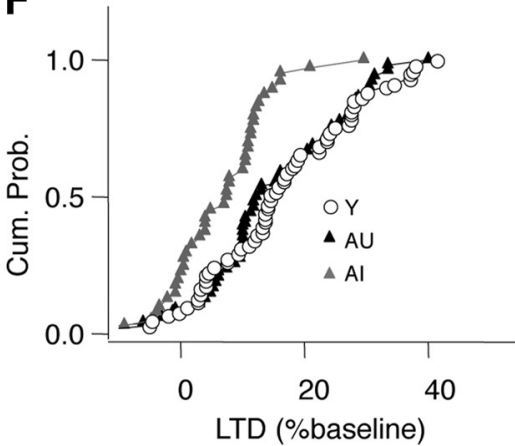

Figure 4. Effects of aging on NMDAR-and mGluR-LTD. $A$, LTD induced with single-pulse LFS (LFS: striped bar) is blocked by 100 , but not in AU rats. $\boldsymbol{E}$, Distributions of the NMDAR-LTD magnitude computed by pooling all the slices in $\mathrm{Y}, \mathrm{Al}$, and AU rats. $\boldsymbol{F}$, Similarly, distributions of the mGluR-LTD for the three groups. The number of slices and rats is indicated in parentheses. Traces on Cand $\boldsymbol{D}$ : average of 10 consecutive responses recorded before (thick line) and $60 \mathrm{~min}$ after conditioning (thin line).

found to correlate with the behavioral performance in young, but not in aged rats; whereas the NMDAR-independent forms of LTP/D correlated significantly with the individual's behavioral performance in the aged, not in the young rats (Lee et al., 2005; Boric et al., 2008). It was of interest, therefore to determine whether the $\mathrm{A} / \mathrm{C} \rightarrow \mathrm{CA} 3$ pathway also shows an age-dependent switch in the relationship between plasticity mechanisms and learning performance. In this analysis we only considered those individual cases in which a given form of plasticity was measured at least three times. The results are summarized in Figure 5. We found that the behavioral index did not correlate with the average magnitude of NMDAR-LTP in either young $\left(R^{2}=0.0008 ; p=\right.$ $0.64)$ or aged $\left(R^{2}=0.00231 ; p=0.85\right)$ individuals (Fig. $\left.5 A\right)$. In contrast, the behavioral index did correlate with the average magnitude of VGCC-LTP in the aged group $\left(R^{2}=0.24 ; p=0.03\right)$, but not 
A
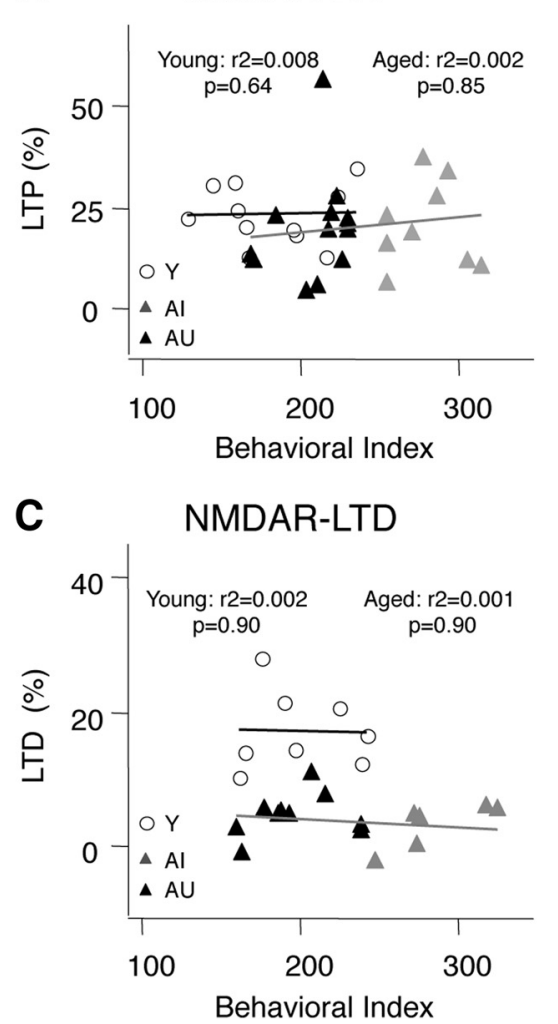
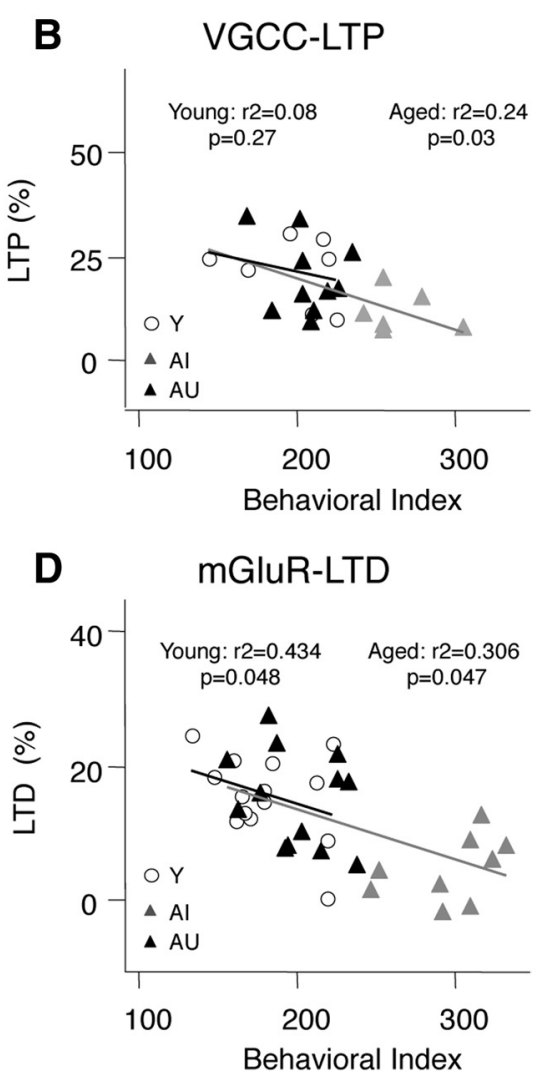

Figure 5. NMDAR-independent forms of LTP and LTD correlate with behavioral performance in $A / C \rightarrow C A 3$ synapses. Relationship between the behavioral score and the average magnitude of NMDAR-LTP $(\boldsymbol{A}), \operatorname{VGCC}-\operatorname{LTP}(\boldsymbol{B}), \operatorname{NMDAR}-\operatorname{LTD}(\boldsymbol{C})$, and mGluR-LTD (D) measured in $\mathrm{Y}(\mathrm{O}), \mathrm{Al}$ (gray triangles), and AU individuals (black triangles). The lines in each graph represent a linear fit on the data from young (black) and aged (Al and AU together, gray) individuals.

in the young group $\left(R^{2}=0.08 ; p=0.27\right.$; Fig. $\left.5 B\right)$. The pattern for LTD

was similar. The average magnitude of NMDAR-LTD did not correlate with the behavioral index in either young $\left(R^{2}=0.0025 ; p=\right.$ $0.90)$ or aged $\left(R^{2}=0.001 ; p=0.90\right)$ rats (Fig. $\left.5 C\right)$, but the average magnitude of mGluR-LTD correlated with the behavioral index in both young $\left(R^{2}=0.434 ; p=0.048\right)$ and aged $\left(R^{2}=0.306 ; p=\right.$ 0.047. Fig. $5 D$ ) groups. These results indicate that the behavioral index correlates only with the NMDAR-independent forms of LTP/D in both young and aged individuals. Thus, unlike in the case of $\mathrm{CA} 1$, in the $\mathrm{A} / \mathrm{C} \rightarrow \mathrm{CA} 3$ pathway the mechanisms of plasticity that correlate with learning performance do not switch during aging but are similarly maintained in rats with intact behavioral performance, regardless of age.

\section{Allosteric enhancers of mGluR5 restore mGluR-LTD in rats The results presented above suggest that the integrity of NMDAR- independent forms of LTP and LTD in the A/C $\rightarrow$ CA3 pathway are crucial for maintaining learning performance during aging. Indeed, the AI and AU groups differ only in the magnitude of NMDAR- independent forms LTP and LTD. It was of interest, therefore, to identify steps in the plasticity induction cascades that are affected by aging. We focused on the induction of mGluR-LTD because it was relatively more affected by age than LTP in AI rats with memory impairments.}

First, we tested whether the capacity to express mGluR-LTD in the $\mathrm{A} / \mathrm{C} \rightarrow \mathrm{CA} 3$ synapses is reduced in $\mathrm{AI}$ individuals. This form of LTD depends on the activation of mGluR5 receptors (Fig. 4B) and in SC $\rightarrow$ CA1 synapses it can be induced by bath application of the group I mGluR agonist DHPG (Palmer et al., 1997; Huber et al., 2000). Indeed, DHPG-induced LTD is extensively used to quantify alterations in mGluR-dependent LTD, particularly in mouse models of neurological diseases (Huber et al., 2002). A dose-response study indicated that the agonist effectively induces LTD at A/C $\rightarrow$ CA3 synapses (Fig. $6 A$; Max: $77.40 \pm 2.77 \%$ at $50 \mu \mathrm{M})$ comparable to that observed in CA1 (76.98 \pm $3.50 \%, n=4$; data not shown; Huber et al., 2000). We used this high dose of $50 \mu \mathrm{M}$ to probe mGluR-LTD in the three groups. Interestingly, unlike the case of mGluRLTD induced by ppLFS, we found that the magnitude of LTD induced by DHPG was not reduced in the AI group (Fig. 6B; Y: $71.87 \pm 5.15 \%, n=7$ slices, 3 rats, AU: $63.33 \pm 5.42 \%, n=9,3, \mathrm{AI}: 53.42 \pm$ $\left.3.80 \%, n=13,7 ; F_{(2,20)}=3.09, p=0.06\right)$.

Next we examined whether boosting mGluRs signaling during ppLFS with the allosteric agonist 3-cyano- $N$-(1,3diphenyl-1H-pyrazol-5-yl) benzamide (CDPPB) rescues mGluR-LTD in AI rats. This drug reportedly enhances mGluRdependent LTD induced in $\mathrm{SC} \rightarrow \mathrm{CAl}$ synapses of young mice (Ayala et al., 2009). A dose-response study indicated that in $\mathrm{A} / \mathrm{C} \rightarrow \mathrm{CA} 3$ synapses $10 \mu \mathrm{M} \mathrm{CD}$ PPB maximally enhances LTD induced by a suboptimal dose of DHPG (DHPG-LTD in control: $90.85 \pm 3.45 \%, n=7$; in $10 \mu \mathrm{M}$ CDPPB: $68.27 \pm 2.64 \%, n=7$ slices, $p<0.01$, $t$ test; Fig. $6 C, D)$. Having confirmed the effectiveness of CDPPB in A/C $\rightarrow$ CA3 synapses, we then tested its effects in mGluR-LTD induced with ppLFS in the three groups. The drug substantially increased the magnitude of mGluR-LTD in slices from the AI group (control: $90.75 \pm 2.83 \%, n=11$; CDPPB: $73.91 \pm 2.73 \%, n=14$ ), and to a lesser extent in the AU and Y groups (Fig. 6E,F). An ANOVA test and a Fisher post hoc test confirmed the significance of the interaction between age groups and drug treatment $\left(F_{(2,76)}=\right.$ 7.437; $p=0.0011)$. This rescue of mGluR-LTD indicates that AI can express mGluR-LTD, but that the mGluR signal during ppLFS is insufficient to fully engage the plasticity cascade.

\section{Discussion}

Substantial evidence indicates that pronounced alterations occur in the CA3 hippocampal subfield during aging (Wilson et al., 2005; Haberman et al., 2008), yet very little is known about how aging affects synaptic plasticity in this region. This paucity of information prompted us to evaluate NMDAR-dependent and independent forms of synaptic plasticity at $\mathrm{A} / \mathrm{C} \rightarrow \mathrm{CA} 3$ synapses in behaviorally characterized aged rats. The principal findings reported are as follows: (1) NMDAR-LTD, but not NMDAR-LTP, becomes impaired during aging; (2) the non-NMDAR-dependent forms of LTP and LTD are both reduced in AI rats; (3) the NMDARdependent forms of plasticity do not correlate with learning performance either in young or aged individuals, whereas the non-NMDAR-dependent forms do so at both ages; and (4) the induction of mGluR-LTD is preserved in unimpaired aged rats and can be rescued in $\mathrm{AI}$ individuals by positive allosteric modulators of 
mGluR5 receptors. Based on the currents findings, we propose that the integrity of non-NMDAR-dependent synaptic plasticity, particularly mGluR-LTD, at $\mathrm{A} / \mathrm{C} \rightarrow \mathrm{CA} 3$ synapses is crucial for maintained cognitive performance in aged rats.

\section{Differential effects of aging on the A/ $\mathrm{C} \rightarrow \mathrm{CA} 3$ and $\mathrm{SC} \rightarrow \mathrm{CA} 1$ pathways}

Synaptic mechanisms have been extensively studied in the $\mathrm{SC} \rightarrow \mathrm{CA} 1$ pathway, which has also become a preferred model for studying normal and pathological synaptic aging. However, our comprehensive analysis of LTP and LTD reported here in $\mathrm{A} / \mathrm{C} \rightarrow \mathrm{CA} 3$ has revealed marked differences in the effects of aging on $\mathrm{A} / \mathrm{C} \rightarrow \mathrm{CA} 3$ synaptic plasticity relative to $\mathrm{SC} \rightarrow \mathrm{CA} 1$. A common feature of aging in the $\mathrm{SC} \rightarrow \mathrm{CA} 1$ pathway is impaired induction of NMDAR-LTP (Rosenzweig and Barnes, 2003), compensated by an enhancement of VGCC-LTP (Shankar et al., 1998; Tombaugh et al., 2002), that is specific to age unimpaired individuals (Boric et al., 2008). In contrast, in the $\mathrm{A} / \mathrm{C} \rightarrow \mathrm{CA} 3$ pathway age does not affect NMDARLTP, and only modestly reduces VGCCLTP in behaviorally impaired individuals.

The most prominent effect of aging in distinguishing cognitive outcomes at $\mathrm{A} / \mathrm{C} \rightarrow \mathrm{CA} 3$ synapses occurred in our studies of LTD. A profound loss of LTD was observed in aged rats with cognitive impairment, affecting both NMDARLTD and mGluR-LTD. Our previous analysis in this outbred Long-Evans model also revealed a general reduction in NMDAR-LTD in CA1, which was compensated by increased mGluR-LTD in unimpaired aged rats (Lee et al., 2005). In $\mathrm{A} / \mathrm{C} \rightarrow \mathrm{CA} 3$ the more profound impairment of NMDAR-LTD was not compensated by increased mGluR-LTD but a robust maintenance of that form of LTD was observed in the unimpaired aged rats. It is notable that the differences in plasticity between $\mathrm{SC} \rightarrow \mathrm{CA} 1$ and $\mathrm{A} / \mathrm{C} \rightarrow \mathrm{CA} 3$ that we have detected were observed under the same experimental conditions and with the exact same induction paradigms used previously (Lee et al., 2005; Boric et al., 2008). Moreover, both pathways share the same type of presynaptic input (axons from CA3 pyramidal cells) indicating that the postsynaptic element determines the outcome of aging.

The two pathways now characterized in this model also differ in how aging affects the relationship between plasticity and learning performance. In $\mathrm{SC} \rightarrow \mathrm{CA} 1$, an age-dependent switch is apparent, with learning performance correlating with NMDAR-dependent forms of plasticity in young rats but correlating with non-NMDAR forms in aged rats (Lee et al., 2005; Boric et al., 2008), whereas in $\mathrm{A} / \mathrm{C} \rightarrow \mathrm{CA} 3$, only the non-NMDAR forms of plasticity correlate with behavioral performance at any age. Thus, successful aging might require a switch of plasticity mechanisms in CA1 and the preservation of mechanisms in CA3. Altogether, the differential changes in synaptic plasticity support the emerging notion that the cellular
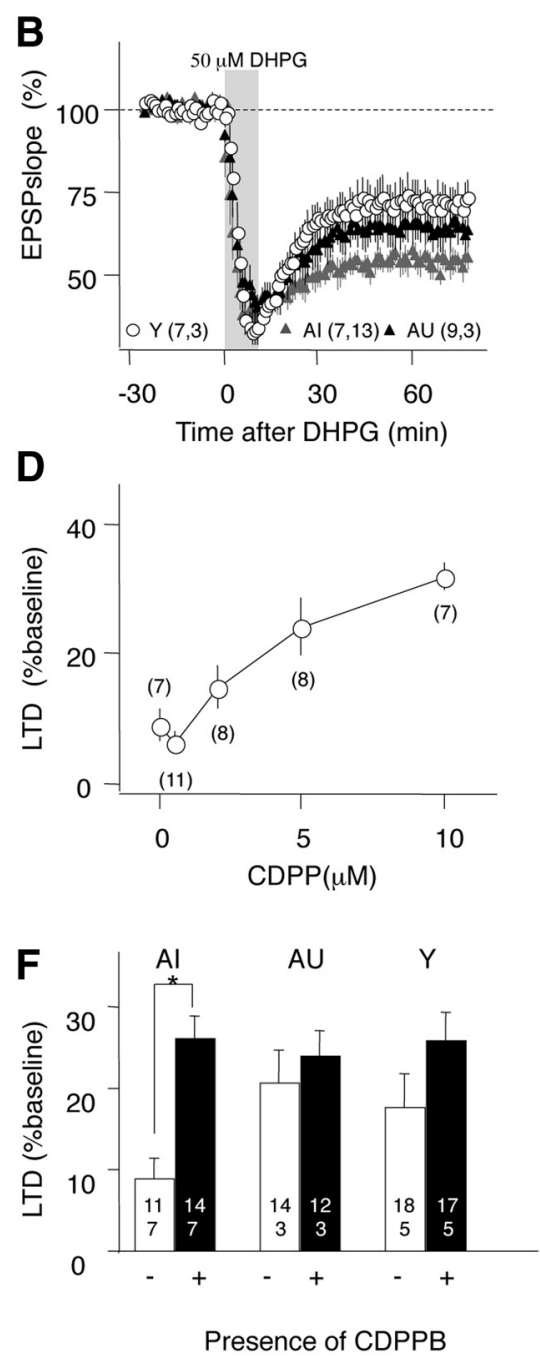

Presence of CDPPB

Figure 6. Reduced induction and normal expression of mGluR-LTD in Al rats. $A$, Bath application of the type I mGluR agonist APV in Al rats. $\boldsymbol{F}$, The facilitation of mGluR-LTD (ppLFS with APV) measured in the three groups (control, white bars; with CDPPB, black bars). The number of slices and rats is indicated in each part; ${ }^{*} p<0.005$.

changes with aging differ across hippocampal circuits (Wilson et al., 2006; Burger, 2010), and calls for a cautionary note on the use of CA1 as a general model of synaptic dysfunction in aging.

\section{Mechanisms of altered plasticity in the aged $\mathrm{A} / \mathrm{C} \rightarrow \mathrm{CA} 3$}

The NMDAR- and mGluR-dependent forms of LTD are the mechanisms of plasticity most affected by age in behaviorally impaired rats at $\mathrm{A} / \mathrm{C} \rightarrow \mathrm{CA} 3$ synapses. It remains to be determined which steps in those plasticity pathways are involved. The loss of NMDAR-LTD in both aged groups was not associated with changes in basal synaptic transmission or in the magnitude of the NMDAR-mediated responses, suggesting a failure downstream from NMDAR activation. An alternative possibility is that aging changes the relative content of NR2a and NR2b subunits of the NMDARs. It has been proposed that NR2b-containing NMDARs are specifically linked to LTD (Liu et al., 2004; Kollen et al., 2008), and subunit replacement can lead to altered LTD and LTP, as observed in some mouse models of Alzheimer's disease (AD) in the CA1 region (Mucke and Selkoe, 2012). However, the 
central premise-that the NR2b subunit promotes LTD over LTP - has been challenged by several studies reporting that NR2b-containing receptors are not essential for LTD (Morishita et al., 2007), but rather promote LTP over LTD (Philpot et al., 2003; Barria and Malinow, 2005). Another possibility has invoked an age-dependent change in intracellular $\mathrm{Ca}^{2+}$ homeostasis as a basis for reduced LTP and enhanced LTD, which is observed in the $\mathrm{SC} \rightarrow \mathrm{CA} 1$ pathway of some rat models of aging (Burke and Barnes, 2006; Oh et al., 2010; Foster, 2012). Note, however, that both altered NMDAR subunit composition and altered $\mathrm{Ca}^{2+}$ homeostasis would predict that NMDAR-LTP should also be affected. Thus, the observation that NMDAR-LTP was unchanged in the aged $\mathrm{AC} \rightarrow \mathrm{CA} 3$ pathway suggests that some other basis underlies alterations in plasticity observed at those synapses. Based on such considerations, we propose that the selective loss of NMDAR-LTD most likely results from an age-dependent decoupling of the LTD cascade from NMDAR signaling, a mechanism that we previously suggested for the loss of NMDAR-LTD in CA1 (Lee et al., 2005). Several lines of evidence suggest that effects of aging on coupling mechanisms might also account for the impairment of mGluR-LTD in AI rats. First, the induction of mGluR-LTD in AI rats can be rescued by greater mGluR5 activation with allosteric modulators, indicating that the capacity to express this form of LTD is not entirely lost. In addition, there is direct biochemical evidence that the coupling between mGluRs and the associated IP3 second messenger pathway is specifically blunted in AI rats (Nicolle et al., 1999). In addition, the ratio of the long and short forms of Homer proteins, synaptic scaffolding molecules that regulate the coupling of mGluR5, has been reported to shift toward uncoupling in AI rats (Ménard and Quirion, 2012). Altogether, such findings suggest that an uncoupling of glutamate receptors could be a common mechanism for the reduction in both forms of LTD in aged rats with cognitive deficits. It remains to be determined whether beside the receptor uncoupling the capacity to express these forms of LTD is also affected by age.

A reduction in $\mathrm{LTD}$ mechanisms at $\mathrm{A} / \mathrm{C} \rightarrow \mathrm{CA} 3$ synapses may play a role in the neural hyperactivity and information encoding deficits observed in the aged CA3 region (Wilson et al., 2005). An age-dependent increase in neural firing was first observed in the outbred rat model used in the current studies. Interestingly, overactivity detected by fMRI localized to the CA3 region has subsequently been confirmed in elderly humans, including patients diagnosed with aMCI (Yassa et al., 2010, 2011). Interventions that reduce excess activity, with improvement in cognitive performance, have successfully translated from preclinical studies of aged rats with memory impairment to a transgenic mouse model of AD and to humans with aMCI (Koh et al., 2010; Bakker et al., 2012; Sanchez et al., 2012; Koh et al., 2013). A link between hyperactivity and impaired synaptic plasticity is further suggested by studies in sensory cortices, where levels of neural activity can profoundly alter the induction of LTD. In particular, manipulations that reduce the GABAergic inhibitory tone and increase cortical excitability impair the induction of NMDAR-dependent LTD; conversely, restoring normal cortical excitability also restores LTD induction (Choi et al., 2002). Thus, if a similar type of regulation operates in $\mathrm{CA} 3$, increased excitability could impair synaptic plasticity, contributing to network dysfunction.

Finally, a loss of both NMDA- and non-NMDA-LTD mechanisms in the $\mathrm{A} / \mathrm{C} \rightarrow \mathrm{CA} 3$ pathway of $\mathrm{AI}$ rats has implications for dysfunction in the computational properties of CA3 circuitry. The $\mathrm{A} / \mathrm{C} \rightarrow \mathrm{CA} 3$ pathway forms a dense auto-associative network believed to mediate pattern completion, through which previ- ously stored representations are retrieved. The CA3 neurons of AI rats exhibit a limited capacity to rapidly encode new information in response to environmental modifications, and instead retrieve previously stored representations (Wilson et al., 2005). Notably, in aged rats the place fields recorded in modified environments are larger than those recorded in familiar environments, as if the new representations were encoded by adding new place fields on top of the older representations (Wilson et al., 2005). A severe deficit in LTD along with the nearly intact LTP in the AC $\rightarrow$ CA3 pathway could provide a mechanism for this "rigidity" in encoding in AI rats. Thus, a loss of LTD triggered by excess of neural activity might also account for a shift toward pattern completion at the expense of pattern separation in the CA3 region. Behavioral evidence indicates that a similar shift occurs in the memory judgments of elderly humans and patients with aMCI in conjunction with excess activation in the CA3/dentate gyrus network detected by fMRI (Yassa et al., 2010, 2011; Bakker et al., 2012). The beneficial effects of reducing hippocampal overactivity, as recently reported by Bakker et al. (2012), could be due to restoring plasticity that is lost in the condition of memory impairment but spared in aging with preserved cognitive abilities.

\section{References}

Ayala JE, Chen Y, Banko JL, Sheffler DJ, Williams R, Telk AN, Watson NL, Xiang Z, Zhang Y, Jones PJ, Lindsley CW, Olive MF, Conn PJ (2009) mGluR5 positive allosteric modulators facilitate both hippocampal LTP and LTD and enhance spatial learning. Neuropsychopharmacology 34:2057-2071. CrossRef Medline

Bakker A, Krauss GL, Albert MS, Speck CL, Jones LR, Stark CE, Yassa MA, Bassett SS, Shelton AL, Gallagher M (2012) Reduction of hippocampal hyperactivity improves cognition in amnestic mild cognitive impairment. Neuron 74:467-474. CrossRef Medline

Barria A, Malinow R (2005) NMDA receptor subunit composition controls synaptic plasticity by regulating binding to CaMKII. Neuron 48:289-301. CrossRef Medline

Bear MF (1999) Homosynaptic long-term depression: a mechanism for memory? Proc Natl Acad Sci U S A 96:9457-9458. CrossRef Medline

Bliss TV, Collingridge GL (1993) A synaptic model of memory: long-term potentiation in the hippocampus. Nature 361:31-39. CrossRef Medline

Boric K, Muñoz P, Gallagher M, Kirkwood A (2008) Potential adaptive function for altered long-term potentiation mechanisms in aging hippocampus. J Neurosci 28:8034-8039. CrossRef Medline

Burger C (2010) Region-specific genetic alterations in the aging hippocampus: implications for cognitive aging. Front Aging Neurosci 2:140. Medline

Burke SN, Barnes CA (2006) Neural plasticity in the ageing brain. Nat Rev Neurosci 7:30-40. CrossRef Medline

Choi SY, Morales B, Lee HK, Kirkwood A (2002) Absence of long-term depression in the visual cortex of glutamic Acid decarboxylase- 65 knockout mice. J Neurosci 22:5271-5276. Medline

Choi SY, Chang J, Jiang B, Seol GH, Min SS, Han JS, Shin HS, Gallagher M, Kirkwood A (2005) Multiple receptors coupled to phospholipase C gate long-term depression in visual cortex. J Neurosci 25:1143311443. CrossRef Medline

Deupree DL, Bradley J, Turner DA (1993) Age-related alterations in potentiation in the CA1 region in F344 rats. Neurobiol Aging 14:249258. CrossRef Medline

Dudek SM, Bear MF (1993) Bidirectional long-term modification of synaptic effectiveness in the adult and immature hippocampus. J Neurosci 13:2910-2918. Medline

Foster TC (2012) Dissecting the age-related decline on spatial learning and memory tasks in rodent models: N-methyl-D-aspartate receptors and voltage-dependent $\mathrm{Ca} 2+$ channels in senescent synaptic plasticity. Prog Neurobiol 96:283-303. CrossRef Medline

Frey U, Huang YY, Kandel ER (1993) Effects of cAMP simulate a late stage of LTP in hippocampal CA1 neurons. Science 260:1661-1664. CrossRef Medline

Gallagher M, Nicolle MM (1993) Animal models of normal aging: relation- 
ship between cognitive decline and markers in hippocampal circuitry. Behav Brain Res 57:155-162. CrossRef Medline

Gallagher M, Burwell R, Burchinal M (1993) Severity of spatial learning impairment in aging: development of a learning index for performance in the Morris water maze. Behav Neurosci 107:618-626. CrossRef Medline

Grover LM, Teyler TJ (1990) Two components of long-term potentiation induced by different patterns of afferent activation. Nature 347: 477-479. CrossRef Medline

Guo Y, Huang S, de Pasquale R, McGehrin K, Lee HK, Zhao K, Kirkwood A (2012) Dark exposure extends the integration window for spike-timingdependent plasticity. J Neurosci 32:15027-15035. CrossRef Medline

Haberman RP, Lee HJ, Colantuoni C, Koh MT, Gallagher M (2008) Rapid encoding of new information alters the profile of plasticity-related mRNA transcripts in the hippocampal CA3 region. Proc Natl Acad Sci U S A 105:10601-10606. CrossRef Medline

Hagena H, Manahan-Vaughan D (2011) Learning-facilitated synaptic plasticity at CA3 mossy fiber and commissural-associational synapses reveals different roles in information processing. Cereb Cortex 21: 2442-2449. CrossRef Medline

Huang S, Treviño M, He K, Ardiles A, Pasquale Rd, Guo Y, Palacios A, Huganir R, Kirkwood A (2012) Pull-push neuromodulation of LTP and LTD enables bidirectional experience-induced synaptic scaling in visual cortex. Neuron 73:497-510. CrossRef Medline

Huber KM, Gallagher SM, Warren ST, Bear MF (2002) Altered synaptic plasticity in a mouse model of fragile X mental retardation. Proc Natl Acad Sci U S A 99:7746-7750. CrossRef Medline

Huber KM, Kayser M, Bear MF (2000) Role for rapid dendritic protein synthesis in hippocampal mGluR-dependent long-term depression. Science 288:1254-1257. CrossRef Medline

Koh MT, Haberman RP, Foti S, McCown TJ, Gallagher M (2010) Treatment strategies targeting excess hippocampal activity benefit aged rats with cognitive impairment. Neuropsychopharmacology 35:1016-1025. CrossRef Medline

Koh MT, Rosenzweig-Lipson S, Gallagher M (2013) Selective GABA(A) alpha5 positive allosteric modulators improve cognitive function in aged rats with memory impairment. Neuropharmacology 64: 145-152. CrossRef Medline

Kollen M, Dutar P, Jouvenceau A (2008) The magnitude of hippocampal long term depression depends on the synaptic location of activated NR2-containing N-methyl-D-aspartate receptors. Neuroscience 154: 1308-1317. CrossRef Medline

Landfield PW, Lynch G (1977) Impaired monosynaptic potentiation in in vitro hippocampal slices from aged, memory-deficient rats. J Gerontol 32:523-533. CrossRef Medline

Lee HK, Kameyama K, Huganir RL, Bear MF (1998) NMDA induces longterm synaptic depression and dephosphorylation of the GluR1 subunit of AMPA receptors in hippocampus. Neuron 21:1151-1162. CrossRef Medline

Lee HK, Min SS, Gallagher M, Kirkwood A (2005) NMDA receptorindependent long-term depression correlates with successful aging in rats. Nat Neurosci 8:1657-1659. CrossRef Medline

Liu L, Wong TP, Pozza MF, Lingenhoehl K, Wang Y, Sheng M, Auberson YP, Wang YT (2004) Role of NMDA receptor subtypes in governing the direction of hippocampal synaptic plasticity. Science 304: 1021-1024. CrossRef Medline

Ménard C, Quirion R (2012) Successful cognitive aging in rats: a role for mGluR5 glutamate receptors, homer 1 proteins and downstream signaling pathways. PLoS One 7:e28666. CrossRef Medline

Morishita W, Lu W, Smith GB, Nicoll RA, Bear MF, Malenka RC (2007) Activation of NR2B-containing NMDA receptors is not required for NMDA receptor-dependent long-term depression. Neuropharmacology 52:71-76. CrossRef Medline

Mucke L, Selkoe DJ (2012) Neurotoxicity of Amyloid beta-Protein: synaptic and Network Dysfunction. Cold Spring Harb Perspect Med 2:a006338. CrossRef Medline

Nicolle MM, Colombo PJ, Gallagher M, McKinney M (1999) Metabotropic glutamate receptor-mediated hippocampal phosphoinositide turnover is blunted in spatial learning-impaired aged rats. J Neurosci 19:9604-9610. Medline

Norman KA, O’Reilly RC (2003) Modeling hippocampal and neocortical contributions to recognition memory: a complementary-learningsystems approach. Psychol Rev 110:611-646. CrossRef Medline

Norris CM, Korol DL, Foster TC (1996) Increased susceptibility to induction of long-term depression and long-term potentiation reversal during aging. J Neurosci 16:5382-5392. Medline

Oh MM, Oliveira FA, Disterhoft JF (2010) Learning and aging related changes in intrinsic neuronal excitability. Front Aging Neurosci 2:2. Medline

O'Reilly RC, Norman KA (2002) Hippocampal and neocortical contributions to memory: advances in the complementary learning systems framework. Trends Cogn Sci 6:505-510. CrossRef Medline

Palmer MJ, Irving A, Seabrook GR, Jane DE, Collingridge GL (1997) The group I mGlu receptor agonist DHPG induces a novel form of LTD in the CA1 region of the hippocampus. Neuropharmacology 36 : 1517-1532. CrossRef Medline

Philpot BD, Espinosa JS, Bear MF (2003) Evidence for altered NMDA receptor function as a basis for metaplasticity in visual cortex. J Neurosci 23:5583-5588. Medline

Rosenzweig ES, Barnes CA (2003) Impact of aging on hippocampal function: plasticity, network dynamics, and cognition. Prog Neurobiol 69:143-179. CrossRef Medline

Sajikumar S, Navakkode S, Frey JU (2007) Identification of compartmentand process-specific molecules required for "synaptic tagging" during long-term potentiation and long-term depression in hippocampal CA1. J Neurosci 27:5068-5080. CrossRef Medline

Sanchez PE, Zhu L, Verret L, Vossel KA, Orr AG, Cirrito JR, Devidze N, Ho K, Yu GQ, Palop JJ, Mucke L (2012) Levetiracetam suppresses neuronal network dysfunction and reverses synaptic and cognitive deficits in an Alzheimer's disease model. Proc Natl Acad Sci U S A 109:E2895-E2903. CrossRef Medline

Schulz D, Huston JP, Jezek K, Haas HL, Roth-Härer A, Selbach O, Luhmann HJ (2002) Water maze performance, exploratory activity, inhibitory avoidance and hippocampal plasticity in aged superior and inferior learners. Eur J Neurosci 16:2175-2185. CrossRef Medline

Shankar S, Teyler TJ, Robbins N (1998) Aging differentially alters forms of long-term potentiation in rat hippocampal area CA1. J Neurophysiol 79:334-341. Medline

Shigemoto R, Kinoshita A, Wada E, Nomura S, Ohishi H, Takada M, Flor PJ, Neki A, Abe T, Nakanishi S, Mizuno N (1997) Differential presynaptic localization of metabotropic glutamate receptor subtypes in the rat hippocampus. J Neurosci 17:7503-7522. Medline

Tombaugh GC, Rowe WB, Chow AR, Michael TH, Rose GM (2002) Theta-frequency synaptic potentiation in CA1 in vitro distinguishes cognitively impaired from unimpaired aged Fischer 344 rats. J Neurosci 22:9932-9940. Medline

Tsukamoto M, Yasui T, Yamada MK, Nishiyama N, Matsuki N, Ikegaya Y (2003) Mossy fibre synaptic NMDA receptors trigger non-Hebbian longterm potentiation at entorhino-CA3 synapses in the rat. J Physiol 546: 665-675. CrossRef Medline

Wilson IA, Ikonen S, Gallagher M, Eichenbaum H, Tanila H (2005) Ageassociated alterations of hippocampal place cells are subregion specific. J Neurosci 25:6877-6886. CrossRef Medline

Wilson IA, Gallagher M, Eichenbaum H, Tanila H (2006) Neurocognitive aging: prior memories hinder new hippocampal encoding. Trends Neurosci 29:662-670. CrossRef Medline

Yassa MA, Stark SM, Bakker A, Albert MS, Gallagher M, Stark CE (2010) High-resolution structural and functional MRI of hippocampal CA3 and dentate gyrus in patients with amnestic mild cognitive impairment. Neuroimage 51:1242-1252. CrossRef Medline

Yassa MA, Lacy JW, Stark SM, Albert MS, Gallagher M, Stark CE (2011) Pattern separation deficits associated with increased hippocampal CA3 and dentate gyrus activity in nondemented older adults. Hippocampus 21:968-979. Medline 